\title{
Risk of rehospitalisation and death for vulnerable New Zealand children
}

\author{
Jane Oliver, ${ }^{1}$ Tim Foster, ${ }^{1}$ Amanda Kvalsvig, ${ }^{1}$ Deborah A Williamson, ${ }^{2}$ Michael G Baker, ${ }^{1}$ \\ Nevil Pierse ${ }^{1}$
}

\begin{abstract}
- Additional material is published online only. To view please visit the journal online (http://dx.doi.org/10.1136/ archdischild-2017-312671).

${ }^{1}$ University of Otago Wellington, Wellington

${ }^{2}$ Peter Doherty Institute for Infection and Immunity, University of Melbourne Melbourne, Australia
\end{abstract}

\section{Correspondence to}

Jane Oliver, Public Health, University of Otago Wellington, 23A Mein St, Newtown, Wellington 6242, New Zealand; jane.rachel.oliver@otago.ac.nz

Received 11 January 2017

Revised 9 June 2017

Accepted 12 June 2017

Published Online First

22 July 2017
Check for updates

To cite: Oliver J, Foster $T$,

Kvalsvig A, et al.

Arch Dis Child

2018;103:327-334.

\section{ABSTRACT}

Objectives There is considerable need to improve the effectiveness of healthcare to reduce morbidity and mortality. Child hospitalisations are influenced by determinants of health, including the home environment. Our aims were: (1) To investigate whether children hospitalised with potentially avoidable conditions thought to be associated with the home have an increased risk of rehospitalisation and death, (2) To investigate whether children hospitalised with particular subgroups of potentially avoidable conditions have an increased risk of rehospitalisation and death, (3) To assess the usefulness of these subgroups for identifying at-risk children.

Design We used four existing groups of potentially avoidable conditions developed based on expert opinion: 1. the potentially avoidable hospitalisations (PAH) group, associated with social/environmental conditions, 2. the potentially avoidable hospitalisations attributable (at least in part) to the home environment (PAHHE) group, 3 . the crowding group, and 4. the Ministry of Health (MoH) group. We analysed national New Zealand hospital discharge data (2000-2014). Rehospitalisation and death were described using Kaplan-Meier curves. Group effectiveness for identifying at-risk children was assessed using Cox proportional hazard models with children hospitalised for non-PAH conditions as comparison. Results In total, 1425085 hospital admissions occurred, for 683115 unique children. Rehospitalisation was relatively common $(71.0 \%)$. Death was rare $(0.6 \%)$. All groups performed moderately well identifying at-risk children. Children with PAH have increased risk of rehospitalisation (adjusted HR (aHR):2.30-3.60) and death (aHR:3.07-10.44). PAH group had highest sensitivity (75.1\%). The MoH group has the highest positive predictive value (rehospitalisation: $86.2 \%$, death: $2.5 \%$ ).

Conclusions Children in the $\mathrm{MoH}$ group are very likely to benefit from housing interventions. Rehospitalisation and early mortality are useful assessment measures. Rehospitalisation exerts a considerable burden, and child deaths are catastrophic.

\section{INTRODUCTION}

There is a considerable global need to improve the effectiveness of healthcare delivery and reduce childhood morbidity and mortality. ${ }^{12}$ New Zealand (NZ) has well-described child poverty, and child hospitalisations have inequitable socioeconomic and ethnic distributions. ${ }^{3}{ }^{4}$ The underlying determinants of health (such as housing quality, nutrition, household crowding and access to effective

\section{What is already known on this topic}

- New Zealand child hospitalisations have inequitable socioeconomic and ethnic distributions.

- Four disease groupings have been developed with the aim of identifying child hospitalisations that are potentially avoidable for a range of reasons, including the potentially modifiable effects of children's home environments.

\section{What this study adds}

- Children hospitalised for conditions considered potentially avoidable have a markedly higher risk of rehospitalisation and death than children hospitalised for other conditions.

- Different sets of screening criteria have varying levels of sensitivity and positive predictive values for identifying these particularly vulnerable children.

healthcare) play a major part in influencing child health outcomes. ${ }^{5-8}$ Failure to address the underlying causes of ill health results in children continuing to experience poor outcomes, with substantial costs to the individuals affected, their families, communities and the government sector. ${ }^{910}$

The hospital setting has long been used as a screening point to identify children who may be at risk of future harm. For example, emergency departments use screening tools that highlight specific patterns and types of injury presentation to prompt hospital staff to consider a non-accidental cause and to arrange for further investigation and referral. ${ }^{11-13}$

Hospital-based screening has the potential to reduce health inequities by identifying families who are in need of support. ${ }^{14}$ Admission to hospital with a preventable disease or injury provides an obvious intervention point, as children are likely to return to the same high-risk environment when they are discharged. For example, NZ children admitted to hospital with respiratory infections have a high prevalence of exposure to adverse housing conditions, which are likely to increase their risk of future ill health. ${ }^{15-20}$

Health researchers and policymakers in NZ have previously identified groups of conditions that can be used as indicators of avoidable hospitalisation. Four such groups are examined in this study. The 
potentially avoidable hospitalisations (PAH) group is designed to identify all potentially avoidable paediatric admissions, with the intention of quantifying the total burden of disease that could be prevented by policy measures addressing the underlying determinants of health. ${ }^{21}$ The second group is designed to identify the subgroup of potentially avoidable hospitalisations attributable (at least in part) to the home environment (PAHHE). ${ }^{1}$ The third group is designed to identify potentially avoidable hospitalisations due to household crowding (crowding). ${ }^{22}$ The final group, currently in use by the NZ Ministry of Health $(\mathrm{MoH})$, includes children with a set of infectious PAH conditions though to be associated with increased risk of acute rheumatic fever (ARF). ${ }^{23}$ Details on how these groupings were determined may be seen in the Supplementary appendix. These groups are unique from others identified in the literature as all have been specifically designed for use in a NZ child population (most others concern adult populations, such as that developed by Jackson and Tobias). ${ }^{24}$ Furthermore, these groups are designed to capture the effect of socioeconomic and environmental determinants of child health on hospital admissions. ${ }^{1}$

The aims of this study were as follows:

1. To investigate whether children hospitalised with potentially avoidable conditions thought to be associated with the home environment have an increased risk of rehospitalisation and death.

2. To investigate whether children hospitalised with particular subgroups of potentially avoidable conditions have a relatively greater increased risk of rehospitalisation and death.

3. To assess the usefulness of potentially avoidable condition subgroups for identifying at-risk children.

\section{METHODS}

\section{Data and ethics}

Full ethics approval was obtained from the University of Otago Ethics Committee (No. HD15/046).

We obtained national hospitalisation and mortality data for the 15-year period 2000-2014 from the NZ National Minimum Dataset (NMDS). The NMDS is a national collection of public and private hospital discharge information. ${ }^{25}$

The encrypted National Health Index (NHI) number was used to identify and link individual patients' hospitalisations over time. No entries lacked encrypted NHI numbers; consequently, all patients' first hospitalisations could be distinguished from later ones.

All computations were performed using the $\mathrm{R}$ language and environment for statistical computing (version 3.2.2). ${ }^{26}$ All survival analyses were performed using the 'survival' $\mathrm{R}$ library (Therneau TM: Survival: A package for Survival Analysis in S, version 2.38, 2015). Bootstrap procedures were performed using the authors' own code.

\section{Condition groupings}

- The PAH group was developed by a panel of child health experts to monitor PAH in NZ.

- The PAH group includes a subset of conditions (the PAHHE group) which might be avoided by 'Central and local government policies which ensured that families with children had access to high quality housing and a safe physical environment...,

- The crowding group is a set of selected PAH conditions associated with household crowding. Diseases selected for inclusion were based on a systematic literature review that identified groups of infectious diseases associated with exposure to household crowding, mainly respiratory and enteric infections. ${ }^{22}$ The crowding group was further refined, based on previously published literature. ${ }^{27}$ Asthma is included on the basis that many episodes are triggered by respiratory infections. ${ }^{28}$

- MoH group, which targets selected infectious PAH conditions thought to be associated with ARF and streptococcal infections, based on expert opinion. ${ }^{23}$ It is the narrowest of the four groups.

Conditions in each of the PAHHE, crowding and $\mathrm{MoH}$ subgroups were selected for further investigation (table 1) using hospital discharge data. Only children hospitalised with the conditions listed while aged 1 to 15 years old were eligible for inclusion. Children aged $<1$ year old were excluded from the analysis due to the unique disease susceptibility patterns that affect this age group. ${ }^{29}$ The total number of child hospitalisations for each group and condition from 2000 to 2014 was noted. Hospitalisations occurring within 30 days of last discharge were considered to be a single event (ie, not counted as rehospitalisations).

\section{Statistical methods}

We calculated whether children ever hospitalised with diseases in the $\mathrm{PAH}, \mathrm{PAHHE}$, crowding and $\mathrm{MoH}$ groups were more likely to be rehospitalised for any cause or die in the study period. As a comparison group, we used all hospitalised children who had never been admitted with a PAH condition.

We used Kaplan-Meier curves to describe the percentage of children who were rehospitalised or died within 5502 days (15 years) post hospitalisation (ie, died before 1 January 2015). Observations were right censored at the end of the study period. HRs were produced using the Cox proportional hazards model to describe the multivariable risk. Where there were multiple readmissions for one individual, the $95 \% \mathrm{CI}$ and variances were calculated with a cluster resampling procedure (the cluster bootstrap); otherwise, standard variance estimates were used (ie, for death). HRs were adjusted for age, sex, ethnicity and deprivation to reduce confounding. Unadjusted and adjusted HRs (HR and aHR) were estimated using the Cox proportional hazards model to describe the univariable and multivariable risk. We tested the proportional hazards assumption using Grambsch and Therneau's global goodness-of-fit test, which tests the assumption that the regression coefficient $\beta$ does not change over time. Survival by single year of age was also calculated.

The prioritised ethnicity classification system identifies individuals belonging to more than one ethnic group and allocates them to a single ethnic group based on a prioritised order of Māori, Pacific and other. For example, a person who identifies as Māori and European will be classified as Māori only. ${ }^{30}$

The New Zealand Index of Deprivation classification system is an index of deprivation that measures the level of socioeconomic deprivation for people in each small area. ${ }^{31}$ Deciles $1-2$ represent people living in the least deprived areas and deciles 9-10 represent people living in the most deprived areas.

\section{Screening effectiveness and efficiency}

We used a standard screening approach to assess the effectiveness of the four disease groups. The sensitivity, specificity and positive predictive value (PPV) for detecting patients, who subsequently developed the condition of interest (rehospitalisation, death), were calculated using the Kaplan-Meier estimates at 5502 days. The number of children needed to screen (NNS) in order to prevent one rehospitalisation or death (assuming a perfect 
Table 1 Conditions included in the PAH, PAHHE, crowding and MoH groups and association with social/environmental variables

\begin{tabular}{|c|c|c|c|c|c|c|}
\hline Condition & ICD codes & $\begin{array}{l}\text { Associated social/environmental } \\
\text { variables }^{1}\end{array}$ & $\begin{array}{l}\text { PAH } \\
\text { group }\end{array}$ & $\begin{array}{l}\text { PAHHE } \\
\text { group }\end{array}$ & $\begin{array}{l}\text { Crowding } \\
\text { group }\end{array}$ & MoH group \\
\hline Acute bronchiolitis & $J 21$ & $\begin{array}{l}\text { Social policy } \\
\text { Housing/physical environment } \\
\text { Ethnic disparities }\end{array}$ & Yes & Yes & Yes & Yes \\
\hline Acute rheumatic fever & $100-102$ & $\begin{array}{l}\text { Social policy } \\
\text { Housing/physical environment } \\
\text { Access to primary care } \\
\text { Ethnic disparities }\end{array}$ & Yes & Yes & Yes & Yes \\
\hline Bacterial meningitis & $\mathrm{G} 00, \mathrm{G} 01$ & $\begin{array}{l}\text { Housing/physical environment } \\
\text { Ethnic disparities }\end{array}$ & Yes & Yes & Yes & Yes \\
\hline Bacterial/unspecified pneumonia & J13-J16, J18 & $\begin{array}{l}\text { Social policy } \\
\text { Housing/physical environment } \\
\text { Access to primary care } \\
\text { Ethnic disparities }\end{array}$ & Yes & Yes & Yes & Yes \\
\hline Bronchiectasis & J47 & $\begin{array}{l}\text { Social policy } \\
\text { Housing/physical environment } \\
\text { Access to primary care } \\
\text { Ethnic disparities }\end{array}$ & Yes & Yes & Yes & Yes \\
\hline Sepsis due to group A streptococcus & A400 & Housing/physical environment ${ }^{22}$ & Yes & No & Yes & Yes \\
\hline $\begin{array}{l}\text { Meningococcal disease (includes meningococcal } \\
\text { meningitis) }\end{array}$ & A39 & $\begin{array}{l}\text { Social policy } \\
\text { Housing/physical environment } \\
\text { Ethnic disparities }\end{array}$ & Yes & Yes & Yes & Yes \\
\hline Viral/other/unspecified meningitis & $\mathrm{A} 87, \mathrm{G} 02, \mathrm{G} 03$ & $\begin{array}{l}\text { Social policy } \\
\text { Ethnic disparities }\end{array}$ & Yes & No & Yes & Yes \\
\hline Viral pneumonia & $\mathrm{J} 12, \mathrm{~J} 100, \mathrm{~J} 110$ & $\begin{array}{l}\text { Social policy } \\
\text { Housing/physical environment }\end{array}$ & Yes & Yes & Yes & Yes \\
\hline Acute nephritic syndrome & N00, N05 & Housing/physical environment ${ }^{42}$ & Yes & No & No & Yes \\
\hline Acute upper respiratory tract infection excluding croup & $\mathrm{J} 00-\mathrm{J} 03, \mathrm{~J} 06$ & $\begin{array}{l}\text { Housing/physical environment } \\
\text { Access to primary care }\end{array}$ & Yes & Yes & Yes & No \\
\hline Asthma & $\mathrm{J} 45, \mathrm{~J} 46$ & $\begin{array}{l}\text { Social policy } \\
\text { Housing/physical environment } \\
\text { Access to primary care } \\
\text { Ethnic disparities }\end{array}$ & Yes & Yes & Yes & No \\
\hline Croup, acute laryngitis, tracheitis & $\mathrm{J} 04 \mathrm{~J} 050$ & Access to primary care & Yes & No & Yes & No \\
\hline Dermatitis/eczema & L20-L30 & $\begin{array}{l}\text { Social policy } \\
\text { Access to primary care } \\
\text { Ethnic disparities }\end{array}$ & Yes & No & No & No \\
\hline Febrile convulsions & R560 & $\begin{array}{l}\text { Access to primary care } \\
\text { Ethnic disparities }\end{array}$ & Yes & No & No & No \\
\hline Gastroenteritis & $\begin{array}{l}\text { A00-A09, R11, } \\
\text { K529 }\end{array}$ & $\begin{array}{l}\text { Access to primary care } \\
\text { Health promotion }\end{array}$ & Yes & No & Yes & No \\
\hline Nutritional deficiency & E40-E64, D50-D53 & $\begin{array}{l}\text { Social policy } \\
\text { Access to primary care } \\
\text { Health promotion }\end{array}$ & Yes & No & No & No \\
\hline Otitis media & $\mathrm{H} 65-\mathrm{H} 67$ & $\begin{array}{l}\text { Social policy } \\
\text { Housing/physical environment } \\
\text { Access to primary care } \\
\text { Ethnic disparities }\end{array}$ & Yes & Yes & Yes & No \\
\hline Skin infection & $\begin{array}{l}\text { L00-L05, L08, } \\
\text { L980, J340, H010, } \\
\text { H000 }\end{array}$ & $\begin{array}{l}\text { Social policy } \\
\text { Housing/physical environment } \\
\text { Access to primary care } \\
\text { Health promotion } \\
\text { Ethnic disparities }\end{array}$ & Yes & Yes & No & No \\
\hline Tuberculosis & A15-A19 & $\begin{array}{l}\text { Social policy } \\
\text { Housing/physical environment } \\
\text { Ethnic disparities }\end{array}$ & Yes & Yes & Yes & No \\
\hline $\begin{array}{l}\text { Vaccine preventable diseases (tetanus neonatorum, } \\
\text { congenital rubella, tetanus, diphtheria, pertussis, polio, } \\
\text { hepatitis B, measles, rubella, mumps) }\end{array}$ & $\begin{array}{l}\text { P350, A33, A34, } \\
\text { A35, A36, A37, } \\
\text { A80, B16, B180, } \\
\text { B181, B05, B06, } \\
\text { B26, M014 }\end{array}$ & $\begin{array}{l}\text { Social policy } \\
\text { Access to primary care } \\
\text { Health promotion }\end{array}$ & Yes & No & No & No \\
\hline Viral infection of unspecified site & B34 & $\begin{array}{l}\text { Housing/physical } \\
\text { environment } \\
\text { Access to primary care }\end{array}$ & Yes & Yes & No & No \\
\hline
\end{tabular}




\begin{tabular}{|c|c|c|c|c|c|c|}
\hline Condition & ICD codes & $\begin{array}{l}\text { Associated social/environmental } \\
\text { variables }^{1}\end{array}$ & $\begin{array}{l}\text { PAH } \\
\text { group }\end{array}$ & $\begin{array}{l}\text { PAHHE } \\
\text { group }\end{array}$ & $\begin{array}{l}\text { Crowding } \\
\text { group }\end{array}$ & $\mathrm{MoH}$ group \\
\hline Constipation & K590 & Access to primary care & Yes & No & No & No \\
\hline Dental (dental caries, pulp, periodontal) & $\mathrm{K} 02, \mathrm{~K} 04, \mathrm{~K} 05$ & $\begin{array}{l}\text { Social policy } \\
\text { Access to primary care } \\
\text { Health promotion }\end{array}$ & Yes & No & No & No \\
\hline Gastro-oesophageal reflux & K21 & Access to primary care & Yes & No & No & No \\
\hline Osteomyelitis & M86 & Ethnic disparities & Yes & No & No & No \\
\hline Rheumatic heart disease & 105-1099 & $\begin{array}{l}\text { Social policy } \\
\text { Access to primary care } \\
\text { Ethnic disparities }\end{array}$ & Yes & No & No & No \\
\hline
\end{tabular}

1 As identified by Anderson et al. (2012) unless otherwise cited.

ICD, International Classification of Diseases; MoH, Ministry of Health; PAH, potentially avoidable hospitalisation; PAHHE, potentially avoidable hospitalisations attributable (at least in part) to the home environment.

intervention could be implemented every time) was calculated as a means of estimating efficiency, as total number of children in the group of interest divided by the number rehospitalised/ dying over the study period. The cluster bootstrap technique was used to calculate the standard error (SE) and 95\% confidence intervals $(\mathrm{CI})$ to indicate the variability of this test. As the NNS is mathematically equivalent to $1 / \mathrm{PPV}$, the SE of the NNS was calculated from the SE of the PPV using the delta method.

\section{RESULTS}

\section{Total hospitalisations and deaths}

Over the period 2000-2014, a total of 1425085 hospitalisations occurred for a total of 683115 children in the 1-15 year old age group. Of these, 619667 hospitalisations occurred for 390220 children in the PAH group and 1469 deaths. In the PAHHE group, 275818 children experienced 413316 admissions and 1180 deaths. Slightly fewer admissions, 365249 occurred for 243791 children in the crowding group, with 1140 deaths. The smallest group, the MoH group, included 67918 children, with 88712 admissions and 805 deaths.

\section{Rehospitalisations}

Overall, 71\% of all hospitalised children were readmitted. Children hospitalised, but never for a PAH condition, demonstrated a much lower risk of being readmitted (compared with children admitted for PAH conditions), with 56.3\% rehospitalised. Children hospitalised with diseases in the $\mathrm{MoH}$ group had the highest risk of rehospitalisation, with $86.2 \%$ rehospitalised at 5502 days following the initial admission. Similarly, there were elevated risks of rehospitalisation in children hospitalised with diseases in the PAHHE group (80.3\% rehospitalised) and the crowding group ( $80.3 \%$ rehospitalised). Table 2 describes the risk of rehospitalisation for any cause following hospitalisation in each of the four groups using children who were hospitalised with a non-PAH condition as the comparison group.

Figure 1 describes the Kaplan-Meier curve for rehospitalisation, following initialhospitalisation for a condition in each group.

\section{Mortality}

Overall, $0.6 \%$ of all hospitalised children died during the study period. Children hospitalised, but never admitted for a PAH condition, demonstrated the highest survival rate, with 99.7\% surviving. Children hospitalised with conditions in the $\mathrm{MoH}$ group demonstrated the poorest survival. At 5502 days post hospitalisation, $97.6 \%$ (95\% CI: $97.2 \%$ to $98.0 \%$ ) of children hospitalised in the $\mathrm{MoH}$ group remained alive (aHR: 10.4), as did 99.1\% (95\% CI: $99.0 \%$ to $99.2 \%$ ) of children hospitalised in the crowding group (HR: 4.00) and 99.2\% (95\% CI: 99.1\% to $99.3 \%$ ) hospitalised in the PAHHE group (HR: 3.31). By comparison, 99.3\% (95\% CI: $99.2 \%$ to $99.3 \%$ ) of children hospitalised for a PAH condition survived (HR: 3.07, Figure 2, table 3).

The proportional hazards assumption was tested and did not hold by group. We therefore fitted spline smoothed curves to the standardised Schoenfeld residuals for covariates in each model using the Therneau and Grambsch's Z test for global goodness of fit, available in the R survival library ( $\mathrm{p}$ for all models $<0.001$ ). Visual inspection showed the assumption was largely true for age at diagnosis, ethnicity, deprivation and sex. For the main exposure, however (hospitalisation for housing-related disease), the assumption did not hold, with $\beta$ declining over time. Grambsch and Therneau suggest that smoothed Schoenfeld residuals provide a good estimate of the true form of $\beta(t)$ when there is a large sample size. This effectively extended the Cox model, allowing $\beta$ to change with time, without specifying the form of

Table 2 HRs describing risk of rehospitalisation or death for any cause following admission with a condition in the PAH, PAHHE, crowding and $\mathrm{MoH}$ groups compared with children hospitalised for a non-PAH condition

\begin{tabular}{|c|c|c|c|}
\hline Hospital admission group & Rehospitalisation risk & Unadjusted HR (95\% Cl) & Adjusted* HR $(95 \% \mathrm{Cl})$ \\
\hline Non-PAH & $56.3 \%$ & 1.00 (reference) & 1.00 (reference) \\
\hline PAH & $78.0 \%$ & $2.19(2.17$ to 2.21$)$ & 2.31 (2.29 to 3.34$)$ \\
\hline PAHHE & $80.3 \%$ & 2.41 (2.40 to 2.43$)$ & 2.49 (2.48 to 2.52 ) \\
\hline Crowding & $80.3 \%$ & 2.47 (2.45 to 2.49$)$ & 2.58 (2.56 to 2.61$)$ \\
\hline $\mathrm{MoH}$ & $86.2 \%$ & 3.35 (3.31 to 3.39$)$ & 3.60 (3.55 to 3.66$)$ \\
\hline
\end{tabular}

${ }^{*}$ Adjusted for age, sex, ethnicity and deprivation.

$\mathrm{MoH}$, Ministry of Health; $\mathrm{PAH}$, potentially avoidable hospitalisation; PAHHE, potentially avoidable hospitalisations attributable (at least in part) to the home environment. 


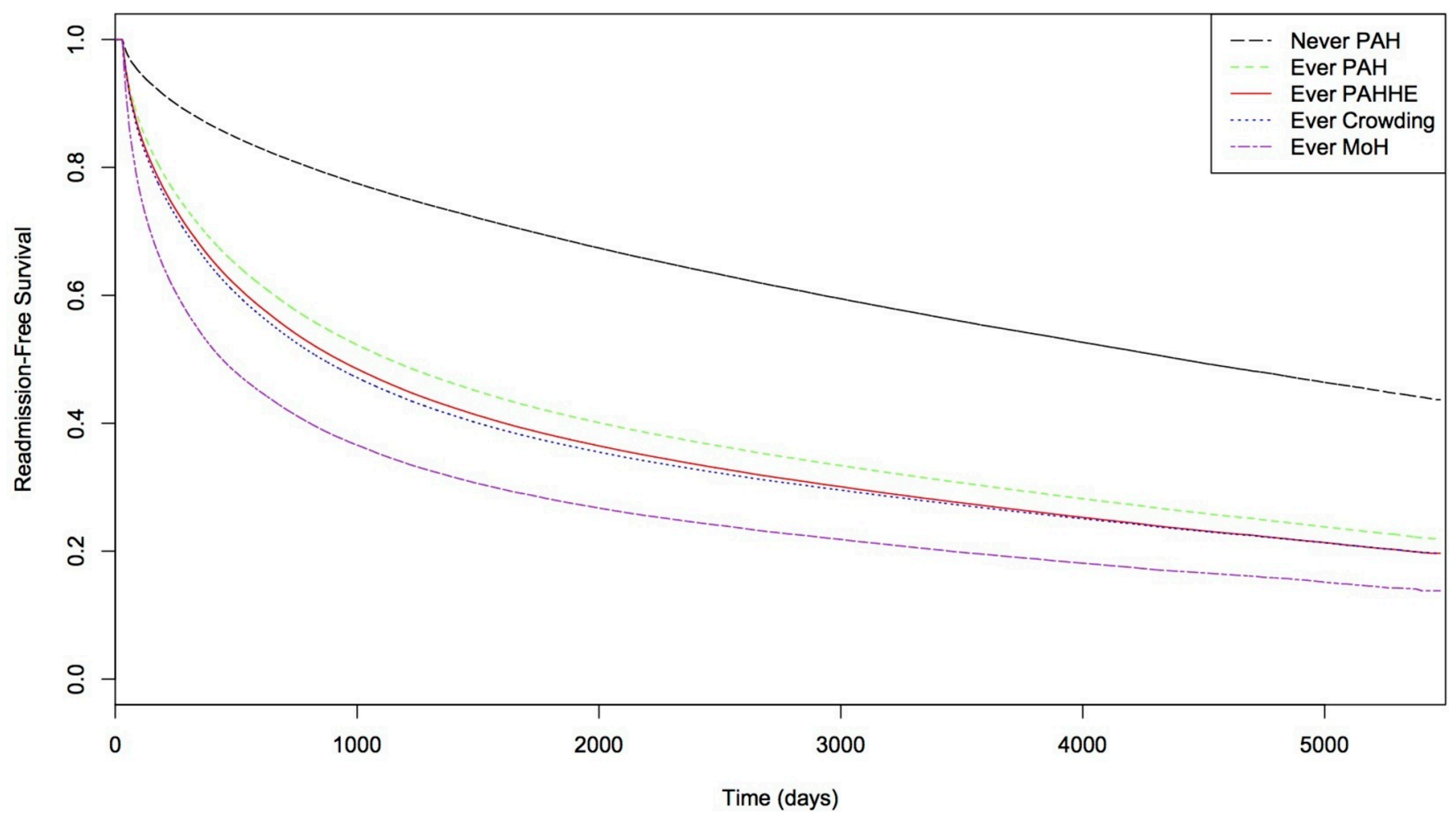

Figure 1 Rehospitalisations following hospitalisation for any cause (excluding PAH conditions), and rehospitalisation following admission for a condition in each disease group. MoH, Ministry of Health; PAH, potentially avoidable hospitalisation; PAHHE, potentially avoidable hospitalisations attributable (at least in part) to the home environment.

this relationship, with the naïve hazard ratios essentially representing 'average' effect (Supplementary appendix figure 1).
Increasing deprivation and Maori or Pacific ethnicity were associated with increased risk of readmission and mortality across

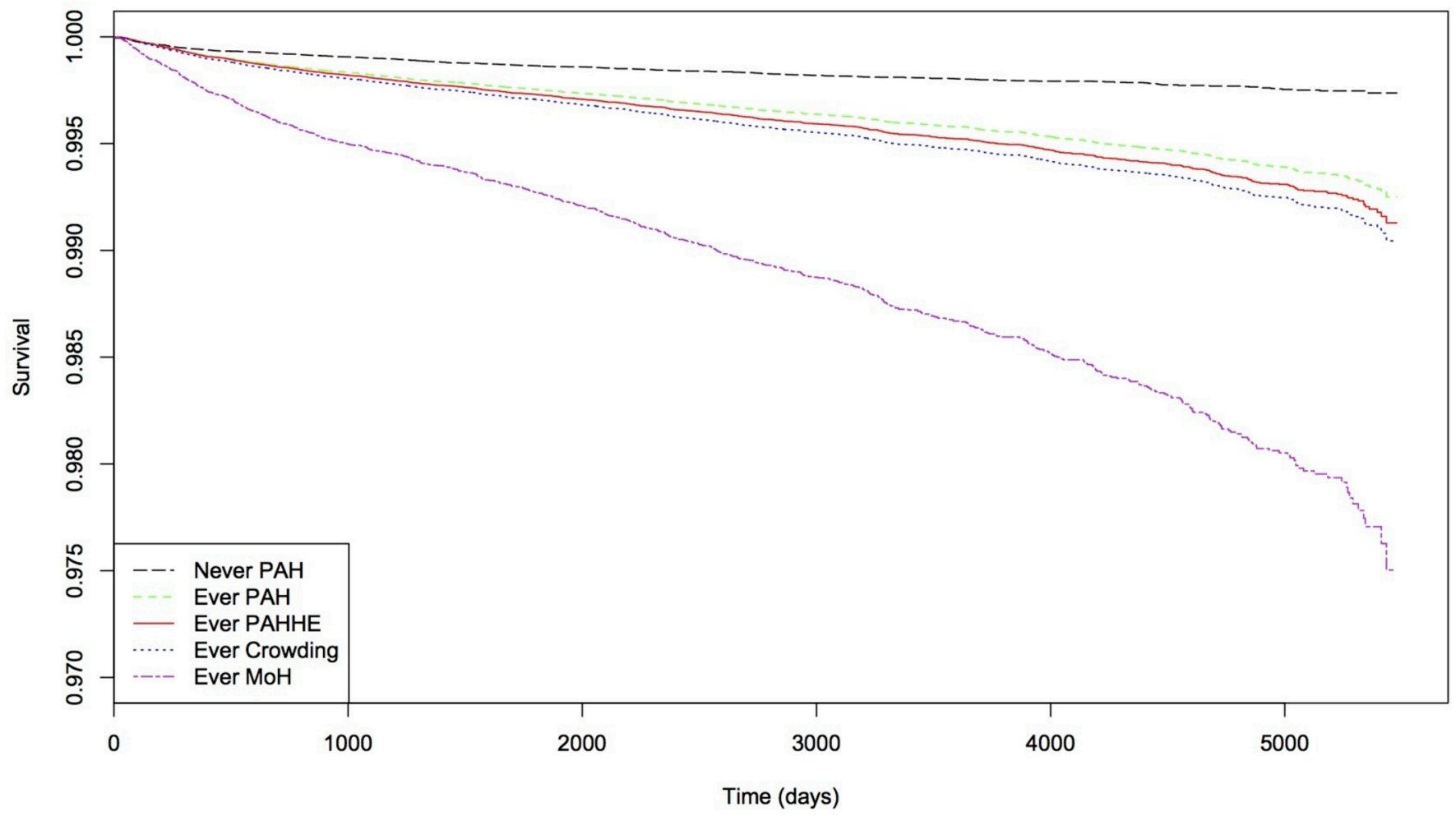

Figure 2 Patient survival following hospitalisation for all causes (excluding PAH conditions) and by group. MoH, Ministry of Health; PAH, potentially avoidable hospitalisation; PAHHE, potentially avoidable hospitalisations attributable (at least in part) to the home environment. 
Table 3 HRs describing risk of death for any cause following hospitalisation in the PAH, PAHHE, crowding and MoH groups compared with children hospitalised for a non-PAH condition

\begin{tabular}{lllc}
\hline Hospital admission group & Survival (\%) & Unadjusted HR (95\% Cl) & Adjusted HR (95\% Cl) \\
\hline Non-PAH & 99.7 & 1.00 (reference) & 1.00 (reference) \\
\hline PAH & 99.3 & $2.23(2.01$ to 2.47$)$ & 3.07 (2.74 to 3.43$)$ \\
PAHHE & 99.2 & $2.45(2.20$ to 2.72$)$ & 3.31 (2.94 to 3.71$)$ \\
Crowding & 99.1 & $2.66(2.39$ to 2.96$)$ & 4.00 (3.55 to 4.50$)$ \\
MoH & 97.6 & $7.03(6.27$ to 7.87$)$ & 10.44 (9.18 to 11.86$)$ \\
\hline
\end{tabular}

*Adjusted for age, sex, ethnicity and deprivation.

$\mathrm{MoH}$, Ministry of Health; PAH, potentially avoidable hospitalisation; PAHHE, potentially avoidable hospitalisations attributable (at least in part) to the home environment.

all groups. Age showed a non-linear relationship with readmission and death risk, with a minimum risk reached at age 5-6 years before risk increased again. Most of the difference between the unadjusted and adjusted models is due to the inclusion of age. For readmissions only, an interaction between ethnicity and deprivation was significant in that Maori or Pacific ethnicity decreased the effect of deprivation, and this was included in the relevant models. All of these variables had much less effect than those for housing related admissions.

\section{Effectiveness analysis}

The following table summarises the performance of four groups using a range of screening performance measures (table 4).

For the rehospitalisation outcome, which is relatively common, three of the groups (PAH, PAHHE, crowding) were all able to detect more than half of the children who were subsequently readmitted (sensitivity 55.0\%-75.1\%). The MoH criteria identified a much lower proportion (sensitivity of $20.2 \%$ ), but the likelihood of children hospitalised in this group being readmitted was higher (PPV of $86.2 \%$ ). The NNS to hypothetically prevent one rehospitalisation was 1.2 for all three subgroups and 1.3 for the PAH group overall. Given the large sample sizes, all CIs were smaller than rounding errors, ie. $< \pm 0.5 \%$.

When investigating mortality, the hospitalisation groups had sensitivities varying from $48 \%$ to $76 \%$. The MoH group demonstrated the highest PPV, but this was still very low at $2.5 \%$ (as would be expected for a rare outcome). The NNS to hypothetically prevent one child's death was 40.2 for the $\mathrm{MoH}$ group, 111.7 for the Crowding group, 121.6 for the PAHHE group and for the PAH group overall was 131.9. The statistics were all normally distributed as demonstrated by plotting normal QQ plots of the bootstrap residuals.

\section{DISCUSSION}

\section{Main findings}

Children hospitalised for conditions that are considered potentially avoidable are more likely to be readmitted to hospital and die compared with children admitted for other conditions. After children are hospitalised with one of the PAH conditions, they are likely to return to situations where factors promoting illness are still present. These factors include housing conditions, such as crowding and cold, damp, mouldy indoor environments. It is also possible that there is less provision of effective treatment and social support for children with conditions included in the $\mathrm{PAH}$ group than provided to children with other conditions. We successfully explored four disease groups which identified potentially avoidable conditions, a number of which were influenced by the home, crowding and the physical environment.

This study showed that the screening performances of these different disease groupings varied markedly. The PAHHE and crowding groups identified the largest proportion of children who subsequently had adverse outcomes, but the trade-off was a lower PPV. The $\mathrm{MoH}$ group on the other hand identified fewer poor health outcomes but had significantly higher PPV and consequently could be seen as more efficient for screening purposes, particularly if resources for follow-up are limited. As a result, it also provided the lowest NNS to prevent a hypothetical death (NNS: 41.7 children).

The $\mathrm{MoH}$ group identifies children at relatively high risk of future morbidity and early death. These children are very likely to benefit from housing interventions to reduce future morbidity and mortality, as all of the conditions included in the $\mathrm{MoH}$ group are also considered to be associated with crowding and/ or the home environment. While acute nephritic syndrome is included in the $\mathrm{MoH}$ group but not in PAHHE or crowding,

\begin{tabular}{|c|c|c|c|c|}
\hline Rehospitalisation & Sensitivity (\%) & Specificity (\%) & PPV (\%) & NNS $(95 \% \mathrm{Cl})$ \\
\hline Non-PAH & 24.9 & 52.2 & 56.3 & 1.8 (1.8 to 1.8$)$ \\
\hline PAHHE & 60.0 & 64.0 & 80.3 & $1.2(1.2$ to 1.2$)$ \\
\hline Crowding & 55.0 & 67.0 & 80.3 & $1.2(1.2$ to 1.2$)$ \\
\hline $\mathrm{MoH}$ & 20.2 & 92.0 & 86.2 & $1.2(1.2$ to 1.2$)$ \\
\hline PAH & 75.7 & 42.9 & 0.7 & 131.9 (125.1 to 139.7$)$ \\
\hline PAHHE & 67.1 & 59.7 & 0.9 & 121.6 (114.7 to 128.5$)$ \\
\hline Crowding & 65.0 & 64.4 & 1.0 & $111.7(105.2$ to 118.2$)$ \\
\hline $\mathrm{MoH}$ & 47.9 & 90.2 & 2.5 & 40.2 (33.9 to 46.5 ) \\
\hline
\end{tabular}

MoH, Ministry of Health; NNS, needed to screen; PAH, potentially avoidable hospitalisation; PAHHE, potentially avoidable hospitalisations attributable (at least in part) to the home environment; PPV, positive predictive value. 
it has recently been shown to be associated with low socioeconomic status. ${ }^{32-35}$

Interventions that alleviate the effects of poor housing and socioeconomic deprivation are likely to have far-reaching effects, impacting positively on child health and benefiting society as a whole. ${ }^{3637}$ Such interventions are likely to be multisectorial. Rehospitalisation is a useful outcome to assess the success of such interventions. As child mortality is rare, it may not be so useful as an outcome measure when evaluating successes of intervention programmes; however, it is a catastrophic event and warrants effective prevention.

\section{Strengths and limitations}

A major strength of this study is the ability to investigate rehospitalisation in a complete national population. The NZ hospitalisation dataset includes a unique person identifier (the NHI) which can be used to track individuals over time.

One limitation concerns the association of diseases included in the PAHHE and other groups with poor quality housing. ${ }^{1}$ While the PAHHE group was developed by child health experts, the extent to which housing influences the rates of these diseases has not been accurately quantified. Furthermore, as our comparison group is children who have been hospitalised (although not for PAH conditions), our analyses may underestimate the true risk of rehospitalisation and mortality because the comparison group has already experienced worse health outcomes than the never-hospitalised child population. The effectiveness of each group to predict rehospitalisation and death in this age group may thus be different to that reported.

\section{Implications}

There are two major implications from this work. The first concerns screening. Children hospitalised for conditions considered potentially avoidable have a markedly higher risk of rehospitalisation and death than children hospitalised for other conditions. Screening can provide health service operators (eg, district health boards) with an opportunity to identify children at increased risk of future admissions, and take action to improve their home circumstances. ${ }^{12} 133839$

These findings also support the need for a multisectoral approach to reducing child health inequities. Housing is an important and clearly modifiable worldwide determinant of child health. The ability of the NZ government sector to effectively deliver housing interventions on a large scale has been clearly demonstrated. The Healthy Housing Programme in Auckland reduced rates of paediatric infectious disease hospitalisations by one-third, ${ }^{40}$ and the Warm Up New Zealand: Heat Smart programme, which provided free insulation to over 300000 homes, produced an estimated net benefit of nearly NZ $\$ 1$ billion. ${ }^{41}$ If a perfect intervention which entirely removed the excess rehospitalisation risk did exist, and it had been applied to all children hospitalised with PAH conditions (ie, $43.5 \%$ of all hospitalised children) over the study period, then a total of 103090 admissions and 347 deaths would not have occurred. The effects of childhood poverty emerge through poorer social, educational and health outcomes. ${ }^{6}$ Such effects can last a lifetime, as seen by the increased risk of cardiovascular disease in adulthood. ${ }^{5}$ Childhood poverty results an increased burden on the healthcare system, as well as on other government and community agencies. ${ }^{569}$ We recommend future research and policy focuses on developing effective housing-related interventions with the aim of reducing the burden of ARF and rheumatic heart disease, and alleviating poverty, improving health equity and enabling social justice throughout society. Such work is likely to be important in all countries where there is significant child poverty.

Hospitalisations for conditions in the $\mathrm{MoH}$ group were strongly associated with rehospitalisation and death, and this striking finding warrants further investigation to identify morbidity and mortality risks specific to these conditions. There is potential to target effective housing interventions towards children hospitalised with conditions in the $\mathrm{MoH}$ group in order to help prevent future morbidity and mortality.

\section{Conclusion}

Future child hospitalisations and deaths may be avoided though appropriate interventions. Large-scale housing interventions may reduce the burden of preventable diseases considerably, if judiciously targeted at vulnerable populations. Scoping for such a programme should begin with an emphasis on incorporating well-integrated referral pathways, and delivering timely intervention to people in need. Useful outcome measures should be pre-identified in order to periodically assess the programme's success. Rates identified in this study may be useful as baseline statistics.

Contributors 10 carried out the analyses, drafted the initial manuscript and carried out revisions, and approved the final manuscript as submitted. TF assisted with carrying out the analyses, reviewed and revised the manuscript, and approved the final manuscript as submitted. AK critically reviewed the manuscript, provided feedback and approved the final manuscript as submitted. DAW critically reviewed the manuscript, provided feedback and approved the final manuscript as submitted. MGB assisted in the study design and guided the write up, critically reviewed and revised the manuscript, and approved the final manuscript as submitted. NP conceptualised and designed the study, provided guidance on the statistical analyses, critically reviewed and revised the manuscript, and approved the final manuscript as submitted. All authors approved the final manuscript as submitted and agree to be accountable for all aspects of the work.

Funding Lotteries Health Research (NZ) - PhD scholarship awarded to JO. Health Research Council of New Zealand awarded a summer studentship research grant to TF through He Kainga Oranga translating housing research to practice for children's health (HRC 15/429).

Competing interests None declared.

Ethics approval University of Otago Ethics Committee.

Provenance and peer review Not commissioned; externally peer reviewed.

(C) Article author(s) (or their employer(s) unless otherwise stated in the text of the article) 2018. All rights reserved. No commercial use is permitted unless otherwise expressly granted.

\section{REFERENCES}

1 Anderson $\mathrm{P}$, Craig E, Jackson G, et al. Developing a tool to monitor potentially avoidable and ambulatory care sensitive hospitalisations in New Zealand children. N Z Med J 2012;125:25-37

2 Ministry of Health. Health targets: Moving Towards Healthier Futures 2007/2008. 2007 http://www.health.govt.nz/publication/health-targets-moving-towards healthier-futures-2007-08-results (accessed 17 May 2012).

3 Ministry of Social Development. The Social Report. 2010 http://socialreport.msd.govt. nz/socialreport (accessed 12 May 2012).

4 Imlach Gunasekara F, Carter K. Persistent deprivation in New Zealand children-results from longitudinal survey data. N Z Med J 2012;125:101-6.

5 Evans GW, Kim P. Childhood poverty and health: cumulative risk exposure and stress dysregulation. Psychol Sci 2007;18:953-7.

6 Turner N. How poverty hurts our children. Nurs N Z 2011;17:33

7 Gracey M, King M. Indigenous health part 1: determinants and disease patterns. Lancet 2009;374:65-75.

8 Pollack CE, Thornton RL, DeLuca S. Targeting housing mobility vouchers to help families with children. JAMA Pediatr 2014;168:695-6.

9 Jaine R, Baker M, Venugopal K. Epidemiology of acute rheumatic fever in New Zealand 1996-2005. J Paediatr Child Health 2008;44:564-71.

10 Milne RJ, Lennon D, Stewart JM, et al. Mortality and hospitalisation costs of rheumatic fever and rheumatic heart disease in New Zealand. J Paediatr Child Health 2012;48:692-7. 
11 National Collaborating Centre for Women's and Children's Health. When to suspect childmaltreatment. National Institute for Health and Care Excellence London, 2009.

12 Woodman J, Lecky F, Hodes D, et al. Screening injured children for physical abuse or neglect in emergency departments: a systematic review. Child Care Health Dev 2010;36:153-64.

13 Chang DC, Knight V, Ziegfeld S, et al. The tip of the iceberg for child abuse: the critical roles of the pediatric trauma service and its registry. J Trauma 2004;57:1189-98.

14 National Collaborating Centre for Determinants of Health. let's talk: Universal and targeted approaches to health equity. Antigonish: National Collaborating Centre for Determinants of Health, 2013.

15 Kelly A, Denning-Kemp G, Geiringer K, et al. Housing risk factors in children admitted to Wellington Hospital. Wellington: He Kainga Oranga/Housing and Health Research Programme, 2013.

16 Halfon N, Newacheck PW. Childhood asthma and poverty: differential impacts and utilization of health services. Pediatrics 1993;91:56-61.

17 Lantos JD, Halpern J. Bullying, social hierarchies, poverty, and health outcomes. Pediatrics 2015;135(Suppl 2):S21-3.

18 Nikiéma B, Spencer N, Séguin L. Poverty and chronic illness in early childhood: a comparison between the United kingdom and Quebec. Pediatrics 2010;125:e499-507.

19 Séguin L, Nikiéma B, Gauvin L, et al. Duration of poverty and child health in the Quebec Longitudinal Study of Child Development: longitudinal analysis of a birth cohort. Pediatrics 2007;119:e1063-70.

20 Wood D. Effect of child and family poverty on child health in the United States. Pediatrics 2003;112:707-11.

21 Craig E, Anderson P, Jackson G, et al. Measuring potentially avoidable and ambulatory care sensitive hospitalisations in New Zealand children using a newly developed tool. N Z Med J 2012;125:38-50.

22 Baker MG, McDonald A, Zhang J, et al. Infectious diseases attributable to household crowding in New Zealand:systematic review and burden of disease estimate. Wellington: He Kainga Oranga/ Housing and Health Research Programme, University of Otago, 2013.

23 Stefanogiannis N. Healthy homes criteria and mortality paper Personal communication. Oliver J. Email correspondance. Wellington, 2016.

24 Jackson G, Tobias M. Potentially avoidable hospitalisations in New Zealand, 1989-98. Aust N Z J Public Health 2001;25:212-21.

25 Ministry of Health. National Minimum Dataset (hospital events). 2012 http://www. health.govt.nz/nz-health-statistics/national-collections-and-surveys/collections/ national-minimum-dataset-hospital-events
26 R Core Team. R:language and environment for statistical computing. Vienna, Austria: R Foundation for Statistical Computing, 2014

27 Baker MG, Barnard LT, Kvalsvig A, et al. Increasing incidence of serious infectious diseases and inequalities in New Zealand: a national epidemiological study. Lancet 2012;379:1112-9.

28 Leung TF, To MY, Yeung AC, et al. Multiplex molecular detection of respiratory pathogens in children with asthma exacerbation. Chest 2010;137:348-54.

29 New Zealand Mortality Data Review Group. 2013. NZ Child and Youth Mortality Review Committee 9th Data Report. Wellington.

30 Ministry of Health. Ethnicity data protocols for the health and disability sector. Wellington, 2004

31 Salmond CE, Crampton P. Development of New Zealand's deprivation index (NZDep) and its uptake as a national policy tool. Can J Public Health 2012;103(Suppl 2):S7-11.

32 McGil Ugwu GI. Acute glomerulonephritis in children of the Niger Delta region of Nigeria. Saudi J Kidney Dis Transp/ 2015;26:1064-9.

33 Etuk IS, Anah MU, Eyong ME. Epidemiology and clinical features of glomerulonephritis in Calabar, Nigeria. Niger J Physio/ Sci 2009;24:91-4.

34 Yap HK, Chia KS, Murugasu B, et al. Acute glomerulonephritis--changing patterns in Singapore children. Pediatr Nephrol 1990;4:482-4.

35 D'Cruz F, Samsudin AT, Hamid MS, et al. Acute glomerulonephritis in Kelantan-a prospective study. Med J Malaysia 1990;45:123-30.

36 Lynch JW, Kaplan GA, Salonen JT. Why do poor people behave poorly? Variation in adult health behaviours and psychosocial characteristics by stages of the socioeconomic lifecourse. Soc Sci Med 1997:44:809-19.

37 Raphael D. Poverty in childhood and adverse health outcomes in adulthood. Maturitas 2011:69:22-6.

38 Higginbotham N, Lawson KA, Gettig K, et al. Utility of a child abuse screening guideline in an urban pediatric emergency department. J Trauma Acute Care Surg 2014;76:871-7.

39 Wood JN, Feudtner C, Medina SP, et al. Variation in occult injury screening for children with suspected abuse in selected US children's hospitals. Pediatrics 2012;130:853-60.

40 Jackson G, Thornley S, Woolston J, et al. Reduced acute hospitalisation with the healthy housing programme. J Epidemiol Community Health 2011;65:588-93.

41 Grimes A, Tim Denne T, Howden-Chapman P, et al. Cost Benefit Analysis of the Warm Up. New Zealand: Heat Smart Programme, 2012

42 Jessamine S. Preventing rheumatic fever. Update on rheumatic fever prevention \& control. Wellington: University of Otago, 2016. 